\title{
ANDALUCÍA, UN ESTILO DE VIDA ORAL
}

\section{Julio Almeida*}

Aquí [en Córdoba] no se puede hacer nada. Se habla mucho y todo se queda en palabras.

Pío Baroja, La feria de los discretos, 1905.

Ya en el Libro egipcio de los muertos pueden leerse palabras de un alma que se confiesa. Esta alma hace confesión negativa y cuenta una larga serie de pecados que no ha hecho y que copio al azar: ¡Oh tú, espíritu! Yo no cometí malas acciones; yo no cometí ningún fraude; yo no robé; yo no maté a mis semejantes; yo no mentí; yo no escuché detrás de las puertas; yo nunca cometí adulterio; yo nunca inicié querellas; yo no me enriquecí de forma ilícita; yo no pequé jamás por hablar demasiado. ${ }^{1}$ Para los antiguos egipcios, por lo visto, hablar demasiado era pecar.

Según las hipótesis más recientes, el hombre empezó a hablar hace unos cien mil años, cuando aún se hallaba en el Paleolítico Inferior, pero evidentemente hay considerables diferencias: cuantitativas y cualitativas. Quisiera mostrar y demostrar que Andalucía se distingue por un estilo de vida predominantemente oral. Los andaluces se mantienen fieles a una forma de vida pregutemberiana. Con las excepciones de rigor, los andaluces leen más bien poco y hablan mucho y muy bien. Esta es la cuestión.

\section{Los europeos}

Los antecedentes de nuestro modo de hablar, como tantas cosas, deben buscarse en la Grecia clásica. Basta leer los diálogos platónicos -un género literario

\footnotetext{
* Catedrático de Sociología de Escuela Universitaria en la Universidad de Córdoba.
} 
que no puede extrañar a un italiano, a un español, a un latino cualquiera- para comprobar que venimos de ellos. Y entre los otros griegos destacan los atenienses. Mientras los lacedemonios eran hombres de pocas palabras de donde laconismo, el habitante de la capital alcanzó fama de buen conversador. En las Leyes, Platón pone en boca del ateniense, que parece ser él mismo: «Todos los griegos imaginan que mi nación tiene en gran aprecio las palabras y es muy habladora.» Pero Megilo, el lacedemonio: «Es propio de la índole lacedemonia, ¡oh huésped!, el dar preferencia siempre a lo más breve. $\rangle^{2}$ Son dos modelos. No se olvide, sin embargo, la concepción mesurada de la vida, típicamente griega: De nada en exceso, aconseja un refrán. Demócrito afirma: «Debe decirse la verdad en lugar de hablar demasiado.» Y también: «Muchos son los que, actuando de la manera más despreciable, hacen gala de los más bellos discursos.» $\aleph^{3}$ En fin, Aristóteles sienta en su memorable Ética a Nicómaco que la virtud se halla en el medio, entre dos extremos viciosos, un defecto y un exceso. Así, la valentía está entre la cobardía y la temeridad; la generosidad, entre la avaricia y la prodigalidad, etc. Nadie le ha superado en este terreno. Aún decimos que en el medio está la virtud, y que tanto se peca por carta de más como por carta de menos.

Pero los europeos tenemos otra profunda raíz en la Biblia. Y los libros sagrados insisten en la necesidad de no hablar demasiado, de hablar lo justo. Echemos una ojeada a los Proverbios. «En mucho charlar no faltará pecado, quien se muerde los labios es discreto.» «Quien guarda su boca guarda su vida, quien suelta los labios marcha a la ruina.» «Toda fatiga trae su ganancia, pero el charlar trae indigencia.» «El que ahorra palabras es hombre que sabe...» Y el pasaje famoso: «Encuentre yo una osa a quien robaron las crías y no a un necio que dice sandeces.» ${ }^{4}$ Más lapidario si cabe, el autor del Eclesiastés desconfía: «Cuantas más palabras, más vanidad.» Pensamientos no muy distintos pueden encontrarse en el Eclesiástico, en los Salmos y en otros lugares. Sucede, sin embargo, que el Antiguo Testamento ha sido poco frecuentado en España; apenas por los clérigos y las pocas personas que sabían latín. (Al comentar a unos judíos de origen español esta propensión nuestra a hablar infatigablemente, me comunican emocionados que a ellos les pasaba lo mismo; que en los gimnasios alemanes, a los muchachos que hablaban mucho les decían que parecían judíos. ¿Judíos en general o sefardies?, inquiero. Sefardíes, castellanohablantes de la coiné de intercambio peninsular durante la Edad Media.)

En la Edad Media europea, benedictinos y cluniacenses insisten en el precepto de no pronunciar palabras ociosas. Y cuando llega la Reforma, los protestantes se entregan a la acción de una manera desaforada; también a la lectura. Lo explicó Max Weber a principios de siglo: «El primero y principal de todos los pecados es la dilapidación del tiempo: la duración de la vida es demasiado breve y preciosa para 'afianzar' nuestro destino. Perder el tiempo en la vida social, en 'cotilleo', en lujos... es absolutamente condenable desde el punto de vista moral.»" Quien haya vivido en Alemania o en Inglaterra, en las áreas reformadas europeas, no habrá dejado de 
advertir la presión social y la correlativa necesidad de hacer cosas, de hablar solamente lo necesario, de aprovechar el tiempo religiosamente. El gran sociólogo precisa en una nota: «El precepto de callar -partiendo de la amenaza bíblica de pena por 'toda palabra inútil' - ha sido, desde los cluniacenses, un método ascético acreditado de educación en el control de sí mismo.» Por lo demás, los cluniacenses, cuya reforma llegó a los reinos cristianos de la península Ibérica en el curso del siglo XI, parece que ejercieron menos influencia al sur del río Tajo.

En España, un san Juan de la Cruz, cuando se refiere a las imperfecciones habituales que obstaculizan el camino del asceta, nombra en primer lugar la costumbre de hablar mucho. ${ }^{6}$ El santo era castellano de Fontiveros, no lejos de Ávila.

Y cuando los europeos transpirenaicos viajan a España se asombran, por lo pronto, de la garrulería del sur.

\section{Los españoles}

Existen numerosos testimonios de franceses, de ingleses o de otros nacionales del continente o de más allá; testigos que luego se detuvieron a narrar sus impresiones, testigos más o menos perspicaces y objetivos, que interesan menos cuando interpretan que cuando miran. Por ejemplo, la condesa D'Aulnoy, que viaja por España en 1679 y 1680 , echa de menos el libro de oraciones y consigna lo que hemos hecho hasta que llegó la televisión: el rezo del rosario en alta voz. Y advierte (no hay que recordar que la condesa se mueve entre señoras de calidad) que las españolas leen poco y escriben menos. Ahora bien: «Se hablaba de todo, comentándose particularmente las noticias de la Corte y de la villa. La conversación era libre y agradable. Fuerza es convenir en que las españolas tienen un ingenio del que nos hallamos a mucha distancia.» ${ }^{7}$ Esta es precisamente la observación que españoles no andaluces hacen sobre éstos: que tienen un ingenio especial que falta en el centro y en el norte.

Parece que George Borrow pensó que en España la lengua es superior a la literatura. Dejemos ahora la literatura. Para quien conozca un poco el temperamento británico, hecho de reserva y self-control, la observación de Borrow creo que significa otra cosa. Visto el asunto desde la taciturnidad inglesa, trabajada durante siglos, ¿no es admirable la lengua hablada de España? ¿No resulta casi fabuloso el idioma del pueblo castellano? ¿No les asombra, sobre todo, el universal espectáculo de gentes gárrulas, todavía no inhibidas por complicadas ideas religiosas?

Parejamente, su amigo Richard Ford, que vivió tres años en Sevilla, de 1830 a 1833, advierte la declamación, las hermosas frases, palabras (subraya, y ahora la dudosa interpretación) «a las que, como los orientales, todos gustan de entregarse, y para las que su idioma grandilocuente les presta facilidad». ${ }^{8}$

En 1862, Hans Christian Andersen, el famoso cuentista danés, viaja por España; no mucho, menos de cuatro meses, pero lo suficiente como para ver lo que 
le parece un espectáculo, porque no sucede en Copenhague, pero cotidiano para nosotros. Muriéndose por entablar conversación en la diligencia con una joven española, pertrechado con un tesoro de cien palabras que no domina, dice una que sabe: estrella. «La palabra cayó como una chispa y prendió la mecha de la conversación en la españolita. Platicaba ella que daba gusto, pero yo no entendía nada. Al amanecer surgió el mar y yo dije el mar, y ya comenzó el diálogo. ¿Inglés?, preguntó ella; danés, contesté; y así iniciamos una conversación; es decir, yo daba la clave, ella componía la melodía. Dije: La poesía de la España, Cervantes, Calderón, Moreto... Yo no hacía más que mencionar nombres, pero por cada uno que yo mentaba crecía la elocuencia de ella.... $\rangle^{9}$ Ya quisiéramos nosotros tener interlocutores así en países cuyas lenguas apenas dominamos. Y aun hablando con algún decoro, ¡qué diferencia! ¡Y qué sorpresa la suya cuando nos oyen y nos ven platicar sin fatiga la lengua de ellos!

Ya en el siglo XX alcanzó cierta notoriedad el neoyorquino Waldo Frank por su España virgen, cuya primera edición data de 1926. Estuvo en México, en la Argentina, en Chile, en el Perú, en Madrid. Aprendió español, y dice del mismo: «Es un lenguaje rápido, caudaloso, ágil y potente. La plástica rigidez del mundo español está en esta lengua de Castilla. Los hombres sorben café o vermut. No son grandes bebedores. Se puede vivir en España un año sin ver un borracho. Están demasiado absortos en la charla para acordarse del alcohol.» ${ }^{10}$ En otros países la gente bebe para combatir la soledad, si bien últimamente ha aumentado el consumo de bebidas alcohólicas en España.

Observación aún más acertada, para lo que nos concierne, aporta el también neoyorquino James Michener, viajero por España durante cuarenta años. Los dos volúmenes de Iberia acreditan que conoce Badajoz, Toledo, Córdoba, Sevilla, Madrid, Salamanca, Pamplona y sus gentes. En Madrid alquiló un coche, con las consiguientes dificultades de aparcamiento. El portero de un restaurante le solía encontrar sitio, pero las buenas propinas que le daba, como un cuarto de dólar, las aceptaba el hombre de mala gana; subió a treinta y cinco centavos, a cuarenta: nada, hosco agradecimiento. Un día fue al restaurante con el director del Reader's Digest en España. El portero le encontró aparcamiento y aquél le dijo estupendo, fantástico, dándole el equivalente a seis centavos. Al sonreír abiertamente el portero, Michener aprendió la lección. Cuando volvió a aparcar, le dio veinticinco centavos gritando: «iEstupendo!» «Y el hombre sonrió de oreja a oreja. Luego le dije 'fantástico' y 'extraordinario', con lo que gané un hueco de afecto en su corazón. Ahora me traía el coche rápidamente, porque como buen español necesitaba palabras tanto como dinero, y las palabras que necesitaba tenían que ser las más expansivas e hinchadas disponibles. En España, las palabras constituyen una especie de divisa que ha de ser derrochada, lo cual no resulta fácil para un norteamericano, pero no hacerlo es perder el espíritu de las relaciones humanas.» ${ }^{11}$ Ellos se educaron en la creencia de que time is money, pero nosotros mantenemos otras convicciones y otros aprendizajes y dilapidamos el tiempo sin tasa y sin culpa. 
Unamuno, tan buen conocedor de muchas literaturas, decía que España es un país «en el que no suelen ser sino oradores por escrito los que por escritores pasan». ${ }^{12}$ Y en Borges, que por su bilingüismo y por su excepcional sensibilidad literaria interesa siempre, encuentro sorprendente confirmación. En diálogo con Osvaldo Ferrari, el gran escritor argentino dice sobre don Quijote y Sancho: «Desde chico tuve, además, conciencia de que hablaban demasiado; me imagino más naturalmente que hubiera largos períodos en que cabalgaran juntos en silencio. Pero como el lector esperaba los sabrosos diálogos, Cervantes no podía permitirse eso. $\rangle^{13} \mathrm{Y}$ en otro momento Borges afirma que estos personajes conversan demasiado bien.

Un belga o un inglés habla cuando quiere, cuando lo necesita y como midiendo las palabras; en esas tierras reformadas, la costumbre no obliga a charlar sin motivo o sin ganas. Es más, se desconfía del palabrero; de quien habla mucho se sospecha que hace poco. Pero en España nos enseñaron que mantener silencio en presencia de los demás es de mala educación; de puro obvio, ni caemos en la cuenta de nuestra verborrea, y platicamos con delectación morosa o sin ninguna gana para que no sospechen de nosotros. Y el mucho hablar implica de suyo dejar los asuntos para mañana. El célebre artículo de Larra «Vuelva usted mañana» podría reeditarse sin cambiar la fecha de 1833. A los españoles se nos niega el derecho a estar callados y desde niños nos obligan a saludar, a ser agradables, quizá a recitar versos de memoria. E ignorantes de tal derecho, lo convertimos en deber de hablar, incluso en derecho a dirigirnos a quien quiera que se ponga a tiro. Damos conversación gratis (el lujo del hombre del norte), con lo que el extranjero, si se aplica, puede hablar español en cuestión de semanas.

Borges y Cela, cada uno por su cuenta, han declarado que el español es fácil. Será fácil para ellos, que lo escriben como quieren, que lo han oído a raudales; o para quienes lo tenemos como lengua materna. Yo creo que el español es tan complicado como los otros idiomas, si se ignora la lingua mater; más complicado que el inglés, de tan difícil pronunciación. El alemán, en cambio, ha de pronunciarse muy bien para que la intrincada estructura sea inteligible. El problema reside en el hecho de que los ingleses y los alemanes del norte hablan más bien poco: leen, meditan, tocan el piano, cultivan el jardín, escuchan música, hacen deporte, pero apenas si conversan. Español aprenderán, sin dificultad mayor, quienes vengan a la península: recibirán clase gratis todos los días, pero si se quedan en su tierra les costará Dios y ayuda. Sé de muchos que lo estudian desde hace años, pero no pueden con él, por ejemplo con el verbo estar.

No se trata, pues, de intuiciones aisladas. Es un hecho de tanto volumen que no necesita demostración. Debería medirse, ¿pero cómo? Al comentar en clase esta cuestión, una alumna me replicó inteligentemente que no es tan difícil: basta contar el tiempo que no estamos hablando. Un sueco, profesor de universidad, que volvía de vacaciones en la Costa Azul, me preguntó en Alemania, en 1972, por qué hablamos tanto los italianos, los españoles, los franceses del sur. ¿Qué responder? Consciente 
de su calculado laconismo, sólo se me ocurrió devolverle la pregunta: ¿Y por qué hablan ustedes tan poco?

\section{Los andaluces}

Demos el último paso. Dentro de la general garrulería española, hay notables diferencias. Entre San Sebastián y Cádiz, ¿quién no las ve? Andalucía es el súmmum de lo que se viene diciendo. En la que los propios andaluces consideran la novela de Andalucía, La feria de los discretos, ubicada en Córdoba, Baroja supo captar el espíritu (dicen que senequista) de personas que pueden discutir interminablemente sin que la realidad se modifique lo más mínimo. Y cuando Borges habla de España, en una entrevista que le hacen en 1962, declara que no descubrió nada en especial, «excepto un generoso estilo de vida oral». ${ }^{14}$ Ahora bien, el escritor se refiere a la Sevilla que había encontrado en 1919 cuando volvía de Ginebra, donde había hecho el bachiller. Y de Suiza a Andalucía, en 1919 como hoy, hay un buen trecho.

Españoles no andaluces (Cela, Alvar y otros) han declarado con rotundidad que en Andalucía se habla con un léxico y una sintaxis riquísimos; otra cosa es la pronunciación y la velocidad. (Yo lo advertí en 1966 cuando me fui a Sevilla, desde Badajoz, para enseñar a leer y escribir a adultos en clases nocturnas, mientras empezaba Filosofía y Letras. En cierto modo, mis alumnos iletrados hablaban mejor que yo, que nunca he sido mudo.) Ahora bien, los andaluces hablan mejor porque se expresan sin continencia, porque se han especializado en conversar.

Alguien dijo que en Madrid, a las siete de la tarde, o das una conferencia o te la dan; y Ortega se refería en ocasiones a un malagueño que le repetía: «Don José, pegue o no pegue, en el culo le pinto un loro», frase que el filósofo estimaba el colmo de la cerrilidad. Pues bien, en Andalucía, a cualquier hora del día o de la noche, se ha de contar con ello. Si uno se encuentra con alguien -amigo, colega, conocido, desconocido-, pegue o no pegue, pegará la hebra, cualquiera de las innumerables hebras existentes; de suerte que nos hallamos en la situación opuesta a la de Robinson en su isla. Acá vive uno enhebrado, le guste o le desagrade, escribiendo en una especie de palimpsesto verbal infinito. Por eso no me parece ninguna rareza la escasa propensión a asociarse que tienen los españoles. Los ingleses, los suecos y los alemanes se asocian porque si no están solos, aislados, desolados; pero nosotros estamos tan inextricablemente conectados que la asociación nos parece un adorno ridículo, una superfetación molesta; es como regalar un bañador a una rana.

¿Y cómo habla el andaluz? Mientras el castellano se expresa con tranquilidad, acaso con cachaza, el paradigmático sevillano necesita hacer piruetas verbales de continuo; el cordobés habla muy alto, como buscando conversación general, con lo que la privacidad es difícil. Como si el silencio fuera malo, se conjura con palabras ubérrimas; por si los bares no bastaran, ahora tenemos televisión hasta en los autobuses. La palabra hablada, y aun el ruido general, es una realidad inconsútil. Y 
sobre todo: las frases deben adornarse, estirarse (estirazarse), transfigurarse en busca de un código lingüístico nuevo. Es la célebre exageración. Si ha llovido poca agua, nuestro interlocutor dirá que él se la bebía toa; si alguien tiene las orejas algo separadas, dirá que parece un taxi con las puertas abiertas; si la jornada futbolística se llenó de empates, la quiniela parecerá un cementerio; si pasa a la vera una mujer gorda (un cómplice puede adelantarse, ¿ha pasao argo?, aquí no ha pasao ná; y si algún forastero incurre en el error de preguntarle al limpiabotas si es cierto lo que dicen de los numerosos maricas de la ciudad, oirá con estupor que depende de los que hayan llegado esta mañana en el tren de la tierra de usted. Todo está ensayado y difícilmente fallará el entrenadísimo verbo andaluz. El andaluz es un virtuoso de la palabra, un atleta con la boca, un artista cuya mala dicción le sirve también para ir componiendo su pirotécnica faena verbal. Enfrentarse a un andaluz significa perder casi con toda seguridad; si ve que corre peligro de ser volteado, se marcha. Ellos torean, no quieren ser toreados. Porque estos duelos verbales (Goffman dice guerra de definiciones) no suelen ser singulares: son actos para la galería, donde nunca faltan espontáneos dispuestos a darle unos capotazos al posible malaje, sieso y esaborío que pretenda modificar las reglas de su enrevesado juego, tan antiguo y tan entrañable.

Ejemplificar exageraciones llevaría tiempo. Cuando en setiembre la temperatura baja por fin a los agradables veintitantos grados, el cordobés asegura formalmente que hace frío; y cuando sube en abril a lo mismo, que hace calor. Nada de mesura, de exactitud, de aproximación a las cosas mismas.

Y apenas leen. Al parecer, un 50 por ciento de los andaluces no han leído un libro en su vida. Ni siquiera periódicos. Si uno sube al autobús y pone detrás, con la mente, el metro de Londres, iqué diferencia! Mientras aquéllos devoran sus periódicos, quizá ocho o nueve de cada diez, éstos rajan sin parar sobre lo divino y lo humano o permanecen en silencio. Últimamente, como decía, en los autobuses urbanos de Córdoba han conjurado el silencio con la matraca de un televisor que no se puede dejar de oír.

Pero una conversación como mandan los cánones helénicos no es tan fácil como parece, una charla sin gritos y sin televisión o música de fondo. El viejo Sócrates dejó dicho de las gentes ignorantes y vulgares que «al no poder, debido a su falta de educación, por sí mismas mantener con las demás una conversación ni con su voz ni con sus razonamientos, alquilan flautistas, pagando cara la voz ajena de las flautas, y a través de sus sonidos se relacionan con los demás. $\rangle^{15}$ Sin duda el gran conversador sabía lo que se decía. Algunos son incapaces de abrir la boca sin acompañamiento de decibelios a tutiplén. Tampoco le falta razón al ginebrino Rousseau: «Generalmente las gentes que saben poco hablan mucho, y las gentes que saben mucho hablan poco: es fácil que a un ignorante le parezca importante todo lo que sabe y lo dice a todo el mundo. Pero un hombre instruido no abre fácilmente su repertorio; tendría demasiado que decir, y ve todavía más que decir tras él; se calla.» ${ }^{16}$ 
Pero no se puede mantener la atención mucho tiempo, ni siquiera los infatigables andaluces, cuya habla se distingue de la castellana -dice Rafael Lapesapor una fuerza espiratoria menor y por una articulación más relajada. ${ }^{17} \mathrm{Y}$ sin duda las palabras acaban perdiendo tensión, significado, valor específico e incanjeable. Tal vez por ese motivo, somos el país europeo que menos se aplica a cumplir el octavo mandamiento de la ley de Dios, el que prohíbe decir falso testimonio y mentir. ${ }^{18}$ Lo curioso es que muchos hasta pregonan su mendacidad. No hace mucho, Julian Pitt-Rivers, que conoce España desde hace más de cuarenta años, ha escrito -en defensa de la realidad de los caracteres nacionales- lo siguiente: «El español sabe mentir como nadie, sobre todo el andaluz, que sabe mentir mejor que todos los italianos y los griegos juntos.» ${ }^{19}$ En mi opinión, es imposible hablar con interés y con veracidad durante horas y horas, como parece imposible jugar bien al fútbol más de noventa minutos. Dije pirotecnia verbal: obsérvense las caras de unos sevillanos después de una larga faena: parece que se apagan; sus músculos faciales (cuando no se sienten mirados, el consejo de Lavater) se vienen abajo, como si les pesara la fatiga de la comedia que han representado.

Las cosas humanas son harto complicadas, pero si se les buscan las vueltas terminan comprendiéndose. Un antropólogo ha sugerido que «con el desarrollo de la alfabetización los ritos de tránsito relacionados con el nacimiento, el matrimonio y la muerte han llegado a ser en gran medida asuntos privados, mientras que en las sociedades orales son públicos». ${ }^{20} \mathrm{Y}$ bien, ¿no es esto lo que sucede en el sur nuestro, procrastinado y reiterativo? En Andalucía la oralidad (Tönnies diría quizá comunidad, Gemeinschaft, todavía no sociedad, Gesellschaft) no ha sido superada por la alfabetización, al menos de modo suficiente; los lectores seguimos siendo aves raras. La verborrea de la gente, el asomarse del que sigue por encima o por debajo o por donde sea, para ver qué hace uno en la ventanilla del banco o de la oficina, sin vergüenza o discreción, el nada recatado tratamiento de la vida privada ajena o la resistencia a instalar cabinas, y a usarlas, para garantizar el voto secreto (las nuevas cabinas telefónicas tampoco son tales, y las de la Compañía Telefónica Nacional en la Gran Vía de Madrid tienen paredes de cartón), todo eso y mucho más ¿no son señales claras de una vida pública que permanece y dura, que prevalece sobre la cuestionada privacidad?

Por volumen de palabras emitidas y por calidad de locuciones inesperadas, por dedicación y puesta en escena, la vida andaluza se caracteriza por un predominio tan absoluto de la palabra hablada, que no es exagerado afirmar que al sur del paso de Despeñaperros nos encontramos inmersos en una vida oral. Y opportune et importune, con gracia o con pesadez, el andaluz hará demostraciones compulsivas de su facundia espectacular.

\section{Unos datos estadísticos}

Una encuesta dirigida por Salustiano del Campo confirma en primer lugar que el nivel de estudios correlaciona con la credibilidad que se tiene en la televisión 
y en la Prensa: quienes sólo tienen estudios primarios creen más en la televisión (27,9 por ciento) que quienes tienen estudios superiores (5,3 por ciento); parejamente, los primeros se fían menos de la Prensa (14,8 por ciento) que los universitarios $(37,5)$. Es bastante lógico. ¿Quién se va a fiar de unas palabras escritas que apenas se frecuentan? Inversamente, la televisión -tan odiada en su versión actual por cualquier persona un poco cultivada- conecta bien con el hombre sin letras.

Y si se atiende a las Comunidades Autónomas, se observa que Andalucía es, con diferencia, la región española que concede más credibilidad a la televisión pública: un 33,3 por ciento de los andaluces creen en ella, frente a un 13,2 de asturianos, 21,4 de catalanes, 13,1 de madrileños, 23,7 de valencianos, 22,3 del resto de España. Como cabe suponer, por lo que se refiere a la Prensa, los andaluces son los que la consideran menos creíble: un insignificante y significativo 7 por ciento de andaluces que creen en la Prensa contrasta con el 31,2 por ciento de asturianos, 21,7 de catalanes, 29,3 de madrileños, 19,9 de valencianos, 22 por ciento del resto de España. ${ }^{21}$

En fin, en la civilidad andaluza, como en la Grecia de los comienzos, reina la palabra hablada de modo incomparable. ${ }^{22}$ En Andalucía ha penetrado la escritura menos que en las otras regiones españolas, menos incluso que en Extremadura y en Castilla-La Mancha, y esa oralidad incontinente y pasmosa no deja de tener su encanto, a veces tan excesivo.

\section{A modo de conclusión}

En el cuarto principio de su «Idea de una historia universal desde el punto de vista cosmopolita», Kant se refiere a la insociable sociabilidad de los hombres, fórmula paradójica que el filósofo explica con claridad. El hombre tiene propensión a socializarse, claro está, pero también a aislarse. Si solamente hace lo primero, si no se aísla de los demás y se recoge, no podrá desarrollar sus talentos naturales; si no se resiste a los demás, sus disposiciones se quedarán en embrión o en barbecho. La resistencia a los demás «despierta todas las facultades del hombre y lo lleva a superar la inclinación a la pereza». «Así se desarrollan gradualmente los talentos y se forma el gusto... Sin la mencionada cualidad de la insociabilidad -que considerada en sí misma no es, por cierto, amable- todos los talentos habrían quedado ocultos por la eternidad en sus gérmenes, en medio de una arcádica vida de pastores... $\rangle^{23}$ Recuérdese también que Kant antepuso en la segunda edición de la Crítica de la razón pura el lema de Bacon, De nobis ipsis silemus. ¿Cuántos andaluces lo aceptarían?

Las cosas humanas tienen dos caras por lo menos. La socialidad andaluza, tan pública y tan generosa (habría que detenerse, more kantiano también, en el egoísmo de los lacónicos europeos, celosísimos de su tiempo, interesados en lo suyo, lanzados siempre a tiro hecho), la generosa socialidad andaluza lastima derechos del individuo al obligarlo a sacrificar su tiempo en aras de un prójimo 
vocinglero, al impedirle quedarse solo en una habitación. Expulsado del hogar desde la más tierna infancia, el español (niño, adolescente o adulto) sólo tiene un extraño hogar-dormitorio y ha de vivir literalmente en la calle, en la taberna, en el pub. Nuestra conversación, compulsiva y lujosa, estorba el no menos necesario lujo de la soledad. Vaya lo uno por lo otro. Como dice un poeta de Sevilla, Manuel Machado, todo es conforme y según. 


\section{NOTAS}

${ }^{1}$ Libro egipcio de los muertos. Salida del alma hacia la luz del día, Edicomunicación, Barcelona, 1988, pp. 234-241.

${ }^{2}$ Las leyes, 641e, 721e, edición bilingüe. Centro de Estudios Constitucionales, Madrid, 1983.

${ }^{3}$ Los filósofos presocráticos III, Gredos, Madrid, 1980, p. 393.

${ }^{4}$ Proverbios 10,$19 ; 13,3 ; 14,23 ; 17,27 ; 17,12$.

${ }^{5}$ La ética protestante y el espíritu del capitalismo, Península, Barcelona, 1969, p. 213.

${ }^{6}$ Obras completas a cargo de Maximiliano Herráiz, Sígueme, Barcelona, 1991, p. 180.

${ }^{7}$ Viaje por España en 1679 y 1680 y cuentos feéricos, 2 vols. I, Iberia, Barcelona, 1962, pp. 174-180.

${ }^{8}$ Ford R., (1974): Las cosas de España, Turner, Madrid, p. 15.

${ }^{9}$ Viaje por España, Alianza, Madrid, 1988, pp. 14-15.

${ }^{10}$ España virgen. Escenas del drama espiritual de un gran pueblo, Aguilar, Madrid, 1989. La cursiva es mía, pp. 264-265.

${ }^{11}$ Iberia. Viajes y reflexiones sobre España, 2 vols. I, Grijalbo, Barcelona, 1986, p. 80.

${ }^{12}$ Epistolario inédito II (1915-1936), edición de Laureano Robles, Madrid, Espasa Calpe, 1991, p. 115.

${ }^{13}$ Borges, J.L. y Ferrari, O., (1992): Diálogos, Seix \& Barral, Barcelona, pp. 328, 116.

${ }^{14}$ Rodríguez Monegal, E., (1987): Borges. Una biografía literaria, FCE, Mexico, p. 142.

${ }^{15}$ Platón, (1980): Protágoras, 347cd, edición bilingüe, Pentalfa, Oviedo.

${ }^{16}$ Emilio, o De la educación, Alianza Editorial, Madrid, 1990, p. 455.

${ }^{17}$ Lapesa, R., "La lengua», en Historia de España Menéndez Pidal, tomo XXXIX, vol. II. Este volumen se subtitula La Edad de Plata de la Cultura Española (1898-1936). Letras. Ciencia. Arte. Sociedad y culturas, Espasa Calpe, Madrid 1994, p. 23.

${ }^{18}$ Véase Orizo, F.A., (1991): Los nuevos valores de los españoles. España en la Encuesta Europea de Valores, Fundación Santa María, Madrid, pp. 94-95.

${ }^{19}$ Cátedra, M., (ed.), (1991): Los españoles vistos por los antropólogos, Júcar Universidad, Madrid, p.38.

${ }^{20}$ Godoy, J., (1990): La lógica de la escritura y la organización de la sociedad, Alianza, Madrid, p. 65.

${ }^{21}$ Campo.,S. del,(dir.), (1993): Estado actual y perspectiva de la sociedad española, Fundación Independiente, Madrid, pp. 67-68.

22 «Porque en la Grecia de los comienzos, la palabra hablada reinaba de manera indiscutible, muy particularmente bajo la forma de clase, 'fama', aplicada a los héroes de la epopeya por los aedas de tipo homérico.» Jesper Svenbro, «La Grecia 
arcaica y clásica. La invención de la escritura silenciosa», en el volumen colectivo dirigido por Carvallo, G. y Chartier, R., (1998): Historia de la lectura en el mundo occidental, Taurus, Madrid, p. 59.

${ }^{23}$ Kant, E., (1964): Filosofia de la historia, Nova, Buenos Aires, p. 44. 